\title{
THE "PENDULUM LAW" - HOW TO EXPLAIN THE COLUMN SHAPE BASED ON COMMON ANOMALIES? PART II
}

\author{
LA "LEY DEL PÉNDULO" - ¿CÓMO EXPLICAR LA FORMA DE LA COLUMNA EN FUNCIÓN DE \\ LAS ANOMALÍAS COMUNES? PARTE //
}

\section{A "LEI DO PÊNDULO" - COMO EXPLICAR A FORMA DA COLUNA COM BASE EM ANOMALIAS COMUNS? PARTE II}

GILLes Norotte ${ }^{1}$

1. Centre Hospitalier InterCommunal des Alpes du Sud, Gap, France.

\begin{abstract}
In Part I, the author defines an organizational law of the body schema: the "pendulum law", describing an ideal biomechanical structure of the spine. Thus, he shows how the common variations and anomalies, whether isolated or associated, modify the standard biomechanical scheme. The variations of isolated "curl/roll up" of the sacrum. Anomalies of the lumbosacral joint in the sagittal (LSS) and/or rotational (LSR) plan. Anomalies of stabilization of the capsule of the hip joint and the sacro-diaphyseal angle. Specific anomalies with grade 1 spondylolysis (SL). Segmental anomalies of the vertebral discs in flexion (Rx). Associated anomalies (SL $+R x+A S L=R x)$. The interest of studying the impact on the vertical construction of the vertebral column, according to the "ideal" scheme is to establish the physiological limits of this gravitational law, to identify the anomalies, to classify schemes and types, and the biomechanical degenerative consequences.
\end{abstract}

Keywords: Spine; Postural balance; Spinal curvatures.

\section{RESUMEN}

En la Parte I, el autor define una ley organizacional del esquema corporal: la "ley del péndulo", describiendo una estructura biomecánica ideal de la columna. De esta forma, demuestra como las variaciones y anomalías comunes, ya sean aisladas o asociadas, modifican el esquema biomecánico estándar. Las variaciones de "enrollamiento" aislado del sacro. Las anomalías de la articulación lumbosacra en el plan sagital (ALS) y/o rotatoria (ALSR). Las anomalías de estabilización de la cápsula de la articulación de la cadera y del ángulo sacro-diafisario. Las anomalías específicas con espondilólisis (SL) de grado 1. Las anomalías segmentarias de los discos vertebrales en flexión $(R x)$. Las anomalías asociadas $(S L+R x+A S L=R x)$. El interés de estudiar el impacto sobre la construcción vertical de la columna, en función del esquema "ideal" es el de establecer los límites fisiológicos de esta ley gravitacional, de identificar las anomalías, de catalogar esquemas y tipos y las consecuencias biomecánicas degenerativas.

Descriptores: Columna vertebral; Balance postural; Curvaturas de la columna vertebral.

\section{RESUMO}

Na Parte I, o autor define uma lei organizacional do esquema corporal: a "lei do pêndulo", que descreve uma estrutura biomecânica ideal da coluna vertebral. Assim, demonstra como as variações e alterações comuns, sejam isoladas ou associadas, modificam o esquema biomecânico padrão. Variações de "enrolamento" isolado do sacro. Anomalias da articulação lombossacral no plano sagital (LSS) elou rotacional (LSR). Anomalia de estabilização da cápsula da articulação do quadril e do ângulo sacro-diafisário. Anomalias específicas com espondilólise (SL) de grau 1. Anomalias segmentares dos discos vertebrais em flexão (Rx). Anomalias associadas $(S L+R x+A S L=R x)$. O interesse de estudar o impacto sobre a construção vertical da coluna vertebral, de acordo com o esquema "ideal" é estabelecer os limites fisiológicos dessa lei gravitacional, identificar as anomalias, classificar esquemas e tipos e as consequências biomecânicas degenerativas.

Descritores: Coluna vertebral; Equilíbrio postural; Cunvaturas da coluna vertebral.

\section{INTRODUCTION}

In our first article (Part I), ${ }^{1}$ we explained why the shape of the spine does not depend on the spino-pelvic parameters, but rather on the "Pendulum Law". Here we provide the main biomechanical schemes that integrate the common variations and anomalies, ${ }^{2}$ whether isolated or associated. We will comment on the impact to the vertical construction of the spine, according to the "ideal" scheme, in order to establish the physiological limits of this gravitational law.

\section{METHOD}

We will successively study different situations frequently encountered in consultations of patients with chronic lumbo-radiculalgia:

- Variations in the isolated "roll up" of the sacrum.

- Anomalies of the lumbo-sacral joint in the sagittal (LSS) and/ or rotatory (LSR) planes.

- Anomalies of stabilization of the capsule of the hip joint and the sacro-diaphyseal angle. 
- Anomalies of grade 1 spondylolisthesis (SL) (specific model).

- Segmental anomalies of vertebral discs in flexion (Rx).

- Associated anomalies $(S L+R x+A S L=R x)$.

\section{Variations in the "roll up" of the sacrum}

We will only consider spines that had no a priori disco-vertebral anomalies above the pelvis.

The variation in the inclination of the sacrum is commonly taken as a reference (Part I). But, in reality, it is more than an anomaly of the "roll up of the sacrum", around the axis of rotation (F). (Figure 1)

The front edge of the sacrum $(\mathrm{B})$ is positioned in a progressively vertical manner from $F$, which corresponds to a progressive opening of the angle of the roll up of the sacrum (S/F/B). (The pelvic incidence linked geometrically to the sacral slope does not take the apex "S" into account.)

This essentially defines an "adaptive" variation in the height of the lumbar apex (L). In the two extreme cases, the apex is "high" for opposing reasons:

- A vertical sacrum has a level sacral slope. The edge B of the sacrum is located behind F. The spine seeks to "create curves" to position the pendulum.

- A horizontal sacrum has an inclined sacral slope: the spine seeks "horizontality" first. The misalignment of T/S usually appears from the upper apex $(\mathrm{L})$ to the $\mathrm{L} 3 / \mathrm{L} 4$ disc. The arm of the lever (S/F) increases.

The sacral slope follows the angles of the roll up of the sacrum $\mathrm{S} / \mathrm{F} / \mathrm{B}$. Point $\mathrm{B}$ is located above the line of tension $\mathrm{P} / \mathrm{F}$, defined by the pendulum. It is then projected differently according to the center of rotation $(F)$. The shapes depend in this case on the conjunction of the pendulum law (The position of $E$ slides along the segment $F / P$ ) and the angle of the roll up and of the sacral slope in "strictu sensu". We noticed a drop in point $P$ approaching the lumbar apex $L$, which rises to compensate the inclination of the slope and explains the elongation of the thorax in height, to the extent that the sacrum "rolls" (horizontalization) and the angle F/P/A opens.

The sacral slope depends on the position of the pendulum, (Figure 2) i.e. on the anomalies above. (It cannot, then, in and of itself explain or classify the shapes of the spine). The posterior misalignment of $\mathrm{T}$ in accordance with $\mathrm{S}$ brings a double stabilizing effect at the level of the pelvis: an increase in the angle of the roll up ( $B$ reaches the vertical of $F$ ), combined with a flattening of the sacral slope under the effect of displacement/lowering behind the pendulum. This leads to a rupture in the pelvic-thoracic line of tension F/B/P.

The head (apex $\mathrm{O}$ ) is positioned following the line of tension of the thoraco-occipital arch, known as the "long" line of tension (P/A/O). In the scheme of reference, the thoraco-occipital line of tension $\mathrm{P} / \mathrm{A} / \mathrm{O}$ is aligned over the pelvic-thoracic line $\mathrm{A} / \mathrm{P} / \mathrm{S}$ : the four points are aligned in this "ideal" configuration $\mathrm{S} / \mathrm{P} / \mathrm{A} / \mathrm{O}$. The pendulum is practically equidistant from $\mathrm{F} / \mathrm{P}$.

\section{Anomalies of the lumbo-sacral joint}

We will refer to the uni- or bilateral transverso-sacral anomalies, or to any anomaly, that involves the first non-functional L5/S1 disc. From the front, this moveable disc is normally high. In profile, the angle of the roll up of the neosacrum (S/F/B, lengthened by the anomaly) very often goes beyond the vertical passing through $F$. The edge of the sacrum (B) is then located in front of the center of rotation $(F)$. (Figure 3 )

The anterior misalignment of $\mathrm{T} / \mathrm{S}$ is the rule. The arm of the lever $\mathrm{S} / \mathrm{F}$ lengthens. The alignment of $\mathrm{T} / \mathrm{S}$ can be obtained in case of association with anomalies of the retrolisthesis type, isthmic lysis, or "compensatory" Rx. (cf. lines below)

The pendulum is in the lower rear position. The sacral pseudo-slope is flattened, the lumbar apex paradoxically low in spite of the horizontalization of the neosacrum.

In all the cases, we noted a modification of the line of tension of the thoraco-occipital arch. Normally, this aligns above the P/A/O (the so-called "long" line of tension). Then the head is aligned above the so-called "short" line of tension T/A/O.
Joint anomalies very often include a "rotatory" note. (Figure 4) Following these rules.

The anomalies of the angle of stabilization of the capsule of the hip joint and the angle of stabilization of the sacro-diaphyseal angle S/F/D.

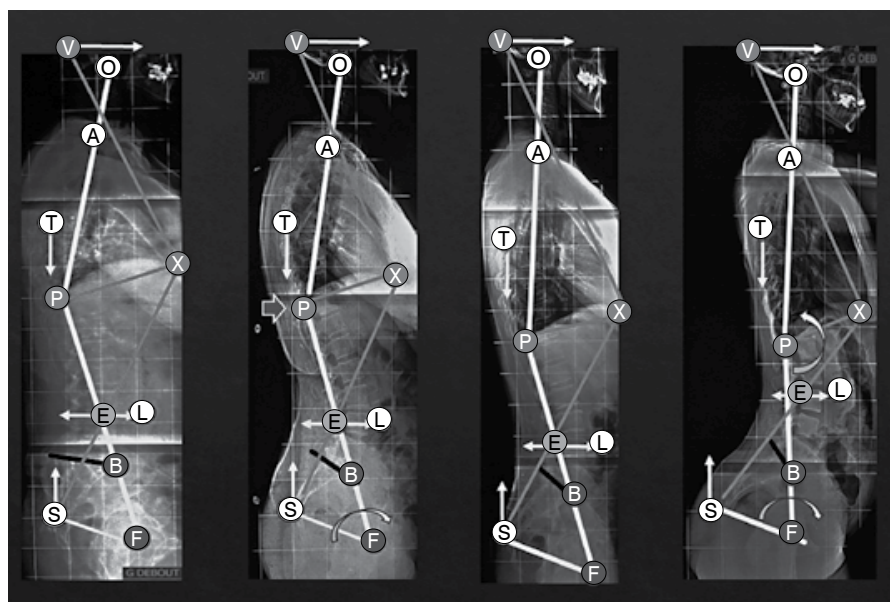

Figure 1. Variations in the angles of the "roll up of the sacrum" S/F/B and the sacral slope.

(A) Point of attachment, (E) Equilibrium of muscle synergies, (F) Femoral heads, (L) lumbar apex joint, (P) Lower posterior-inferior pulmonary apex, (S) sacral apex, (T) Thoracic apex (X) lower anterior pulmonary apex.

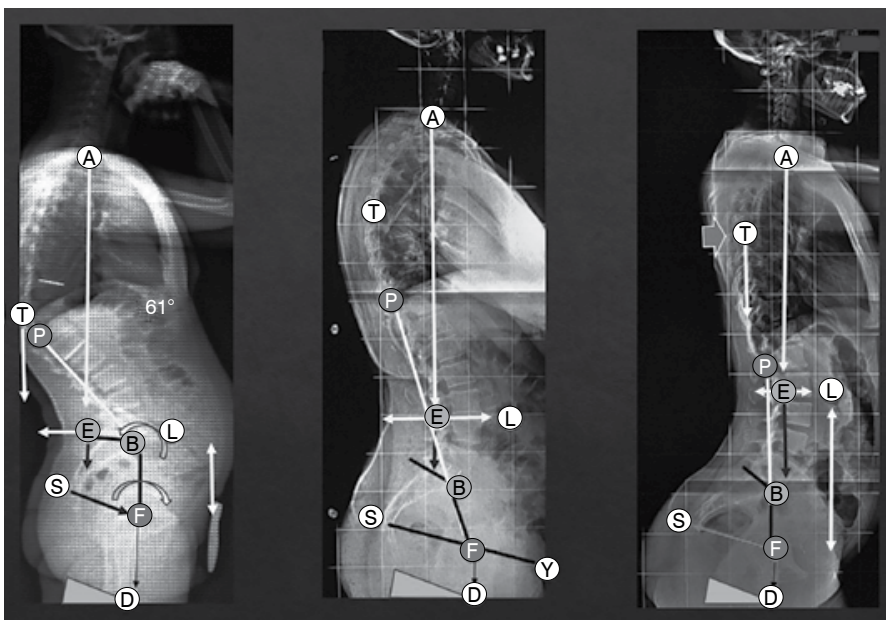

Figure 2. Flattening of the sacral slope in accordance with the anomalies above: rupture of the pelvic thoracic line $\mathrm{F} / \mathrm{B} / \mathrm{P}$, posterior $\mathrm{T} / \mathrm{S}$ misalignment. (A) Point of attachment, (E) Equilibrium of muscle synergies, (F) Femoral heads, (L) lumbar apex, joint, (P) Lower posterior-inferior pulmonary apex, (S) sacral apex, (T) Thoracic apex, (Y) Symphysis.

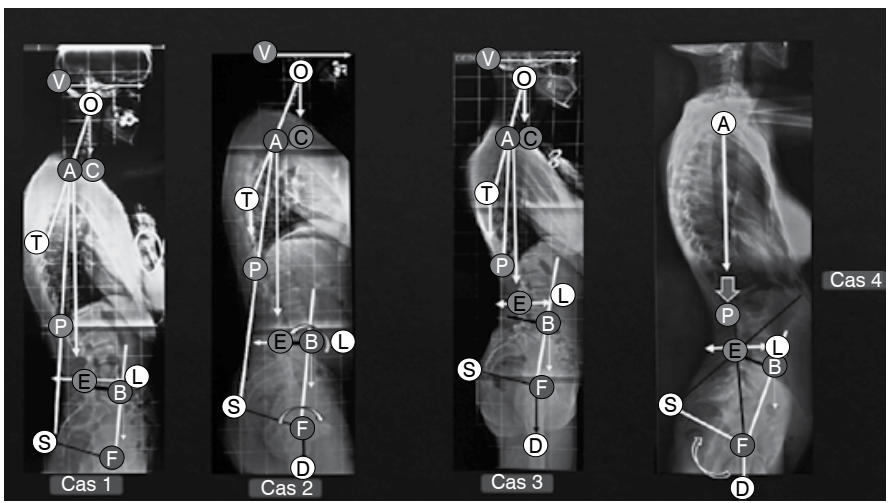

Figure 3. Isolated anomalies of the lumbo-sacral joint (LSJ): Increase in the angle of roll up by the neosacrum case $4 \mathrm{~S} / \mathrm{F} / \mathrm{D}$.

(A) Point of attachment, (E) Equilibrium of muscle synergies, (F) Femoral heads, (L) lumbar apex joint, (P) Lower posterior-inferior pulmonary apex, (S) sacral apex, (T) Thoracic apex. 
The angle of "stabilization of the capsule of the hip joint" has been defined in accordance with the horizontal passing through the center of the femoral heads at an angle between $15^{\circ}+/-4^{\circ}$, which leads to assume vertical femurs. There are anomalies in which this angle reaches $>20^{\circ}$ ("diaphysis D" femurs) to maintain the femurs in a vertical position.

The sacro-diaphyseal (S/F/D) angle of stabilization changes to stabilize the pendulum. (Figure 5) The association of an anomaly of the lumbo-sacral joint with an anomaly of the $S / D$ angle of stabilization represents one of the physiological limits of pendulum law " $A$ ". Within its limiting shapes (case no. 4), the lowering of point $P$ is greater (elongation of the lungs) and the sacro-diaphyseal angle (S/F/D) opens.

We also note opposing shapes with a null angle of stabilization of the capsule of the hip joint with a vertical sacrum.

\section{Grade 1 spondylolisthesis: there is "sometimes" a "specific" biomechanical scheme}

Due to its hyper-mobility in extension, this anomaly changes according to the biomechanical scheme. The pendulum $(A)$ is aligned directly above $S$ following its verticality, reforming an anatomical triangle, aligning the $Y / L / A$ apex as an "ideal" scheme. But the functional organizing scheme is based on the "equidistant" construction of T/L from the cervical pendulum " $\mathrm{C}$ ".

These rules give a specific shape and biomechanical scheme to the spine. (Figure 6) The lumbar apex is lower than normal, except when there is an associated anomaly (of the angle of stabilization, as in case no. 4, for example). The angle of stabilization of the capsule of the hip joint closes. The head positions itself over the "short" thoraco-occipital line of tension T/A/O.

But not all lyses adopt this scheme according to the associated anomalies.

\section{"Rx type" disco-vertebral anomalies in flexion}

These are disco-vertebral anomalies that function in flexion and are responsible for early descending discogenic cascades. They often cause retrolisthesis " $\mathrm{R}$ " (cf. EFDS classification). They generally involve 2 or 3 discs (that is, " $x$ " discs). They are called "Rx" and numbered by the lowest level of retrolisthesis from bottom to top (disc L5/S1=1, $L 4 / L 5=2$, etc.). We found them at all levels of the spine, defining the shapes and the specific biomechanisms. (Figure 7)

In order to respect the pendulum law (Figure 8), these develop a subjacent compensation in lordosis, raising the thoracic apex to compensate when the anomaly is low $(<\mathrm{R} 4 \mathrm{x})$, flattening the thorax. In higher anomalies that cannot compensate above the anomaly, we noted a lowering of the thoracic apex $\mathrm{P}$ and characteristic subjacent hyperlordosis. The posterior misalignment generally appears for anomalies higher than level R3x. The arm of the lever (S/F) is shortened.

All have a low lumbar apex and a flattening of the sacral slope. (Figure 2)

In the absence of other anomalies, the line of tension of the thoraco-occipital arch $\mathrm{P} / \mathrm{A} / \mathrm{O}$ extends to $\mathrm{R} 5 \mathrm{x}$

High thoracic shapes (>R6x) explain rounded shoulders with posterior T/S misalignment but without visible retrolisthesis. The positioning of the head is aligned above the short arch T/A/O. In the extreme shapes (Figure 9), the pendulum law forces the opening of the sacro-diaphyseal angle in order to maintain balance.

\section{Associated shapes}

The association of spondylolisthesis (SL) and a high type $\mathrm{Rx}$ anomaly (SI1 + R8x) suppresses this sacro-diaphyseal "tension of synergic opening". The rules of construction are then those of grade 1 spondylolisthesis (Figure 1), but the arch of the thoraco-occipital tension follows the line $\mathrm{P} / \mathrm{A} / \mathrm{O}$.

\section{DISCUSSION}

The pendulum law enables an explanation of the different shapes and biomechanical schemes of the spine integrating the variables and the common anomalies of construction, encountered in $95 \%$ of the patients seen in consultations for chronic lumbo-radicular pain who generally presented these small anomalies responsible for specific discogenic cascades.

The analysis of these schemes lets us define the limits of the "physiological" integration of this gravitational law. It can obviously be called into question for more serious anomalies that fall outside of this profile.

We observed three frequent types of adaptation:

- The line of tension of the "long" thoraco-occipital arch P/A/O

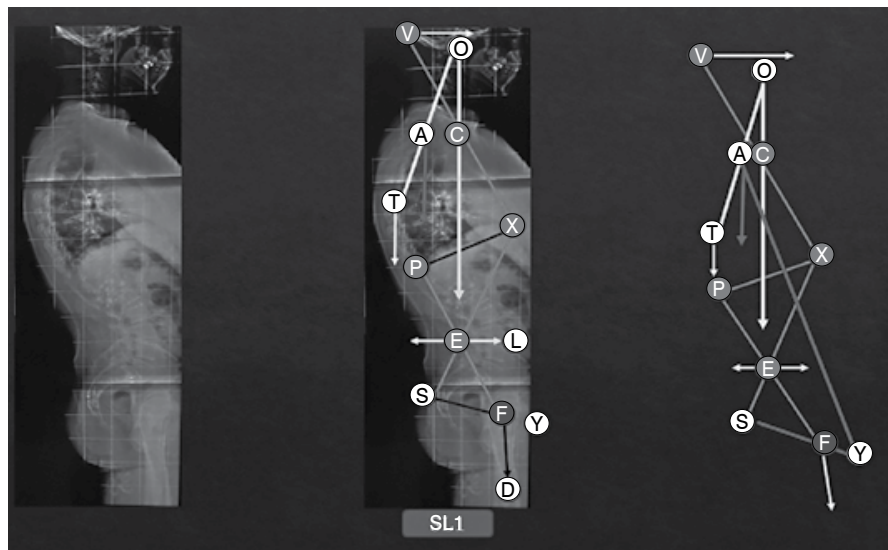

Figure 4. Specific spondylolisthesis (S1) scheme: cervical pendulum. (A) Point of attachment, (E) Equilibrium of muscle synergies, (F) Femoral heads, (L) lumbar apex joint, (P) Lower posterior-inferior pulmonary apex, (S) sacral apex, (T) Thoracic apex, (X) lower anterior pulmonary apex, $(Y)$ Symphysis.

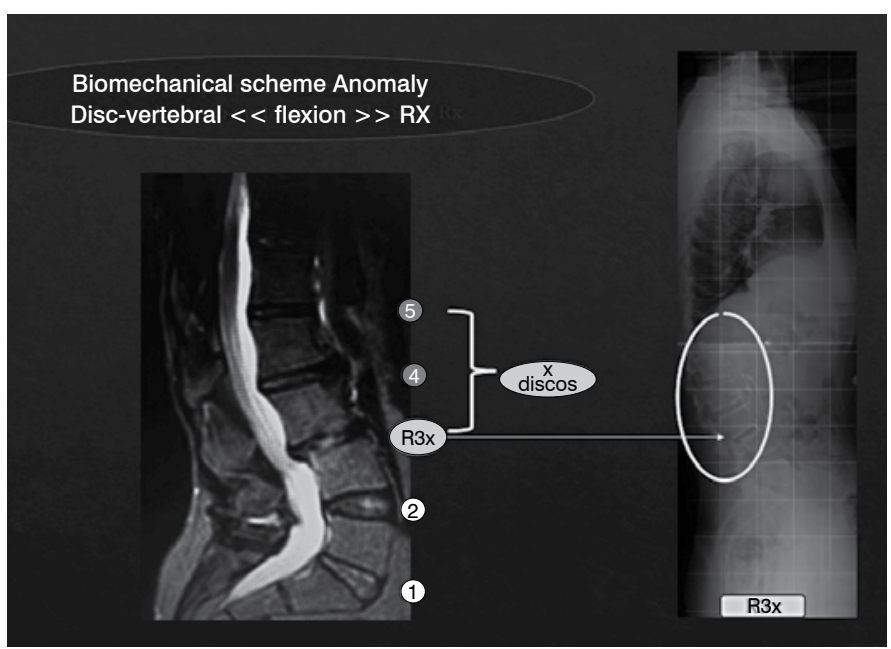

Figure 5. Rx type disc anomaly in flexion.

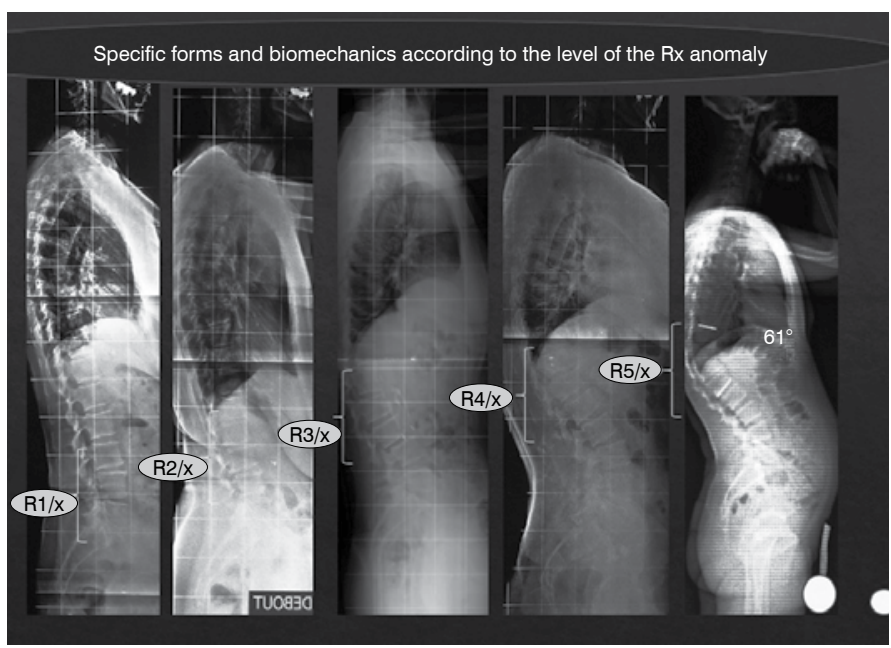

Figura 6. Anomalias discovertebrales en flexion (tipo Rx) según el nivel. 
54

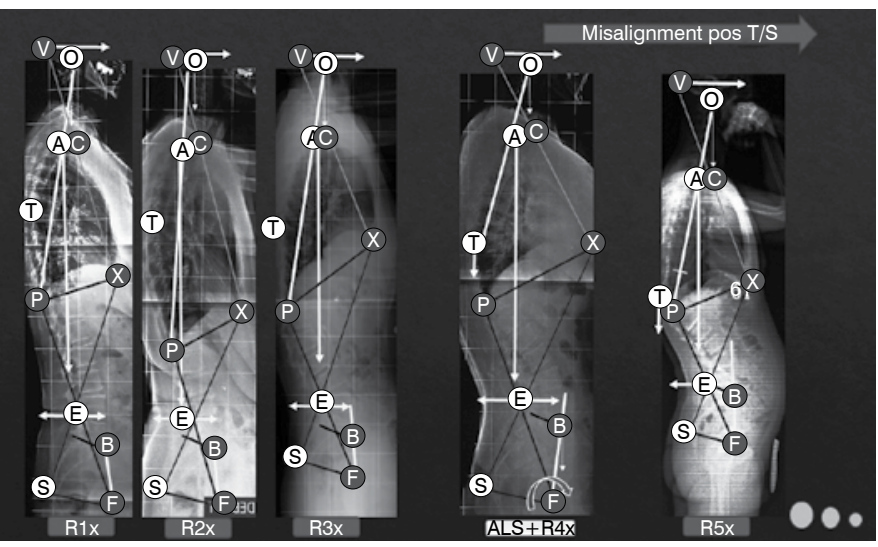

Figure 7. Integration of Rx type anomalies by the pendulum law. (A) Point of attachment, (E) Equilibrium of muscle synergies, (F) Femoral heads, (P) Lower posteriorinferior pulmonary apex, (S) sacral apex, (T) Thoracic apex, (X) lower anterior pulmonary apex.

is modified by a short line of tension $\mathrm{T} / \mathrm{A} / \mathrm{O}$ when there is a situation of "functional shortening of the lumbar muscle synergies": anomaly of the angle of stabilization, sagittal (LSS) and rotatory (LSR) anomaly of the lumbo-sacral joint, grade 1 isthmic lysis, high Rx type kyphosis.

- The opening of the sacro-diaphyseal angle of stabilization is observed whenever an anomaly puts the pendulum law into play because of its "wideness" in opposing situations (LSJ) or high Rus.

- Finally, pendulum law "A" slides towards that of pendulum " $\mathrm{C}$ " becoming the organizer of the functional sagittal scheme in some specific cases of grade 1 spondylolisthesis.

CONCLUSION

The biomechanical schemes in the sagittal plane of the spine

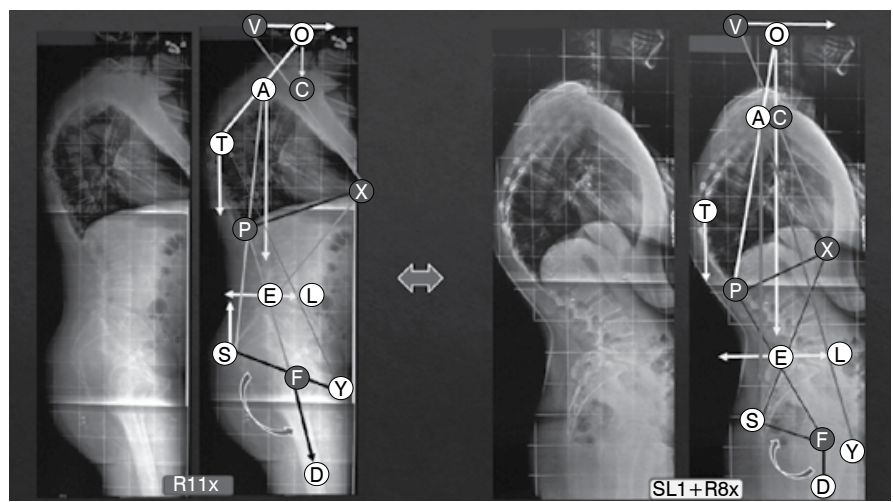

Figure 8. High $\mathrm{Rx}$ type anomaly associated with lysis $(S L=R x)$. (A) Point of attachment, (E) Equilibrium of muscle synergies, (F) Femoral heads, (L) lumbar apex, joint, (P) Lower posterior-inferior pulmonary apex, (S) sacral apex, (T) Thoracic apex, (X) lower anterior pulmonary apex, (Y) Symphysis.

that integrate the common anomalies are "governed" by the "pendulum law" in a huge majority of cases. The interests are several in defining these schemes:

To classify in a precise manner the sagittal shapes according to the anomalies of construction.

To study their functional biomechanics in order to analyze and classify the degenerative cascades in the sagittal/coronal plane.

To exchange the classical type "monoplanar sagittal, angular, and static analysis of degenerative pathology and its vertebral semantics for discogenic semantics and a biomechanical perspective.

All the authors declare that there are no potential conflicts of interest regarding this articles.

CONTRIBUTIONS OF THE AUTHORS: The author of this manuscript that describes an institutional study is GN.

REFERENCES

1. Norotte Giles, La "ley del Péndulo" o como explicar la form 3D de la column? Proposicion de un esquema biomecánico de una column ideal. Revista Chilena de Neurocirugia. 2015; 41:8-13.
2. Norotte Files, Lo du Pendule : comment se modified le shéma biomécanique sagital de la colone en function does anomalies courantes? Rachis. 2014;(6):12-15.

Coluna/Columna. 2018;17(1):51-4 